\title{
REMOÇÃO DE ZINCO DO EFLUENTE LÍQUIDO DE UMA INDÚSTRIA DE GALVANOPLASTIA
}

\author{
F. B. SCHEUFELE ${ }^{*}$, C. RIBEIRO ${ }^{1}$, M. G. SAUSEN ${ }^{1}$, T. LOQUETE ${ }^{1}$, D. E. G. TRIGUEROS ${ }^{1}$, C. \\ E. BORBA ${ }^{1}$ \\ ${ }^{1}$ Universidade Estadual do Oeste do Paraná, Departamento de Engenharia Química \\ *e-mail: fabianoscheufele@gmail.com
}

\begin{abstract}
RESUMO
A indústria de galvanização caracteriza-se pela geração de efluentes contaminados com metais pesados, logo seu tratamento se faz necessário antes do descarte em corpos hídricos. Neste sentido, o objetivo do trabalho foi avaliar o potencial de remoção de zinco do efluente líquido de galvanoplastia pelo processo de troca iônica em sistema fechado e batelada. Para tanto, a caracterização do efluente foi realizada pelas análises de metais pesados (TXRF), pH, DQO, sulfatos, fosfatos e óleos e graxas. Foram realizados experimentos preliminares para avaliar o efeito do $\mathrm{pH}$ inicial e DQO para o efluente bruto e também filtrado. Estudos cinéticos e de equilíbrio foram realizados para o efluente real e também para uma solução sintética de zinco, nos quais realizou-se modelagem matemática para determinação da etapa limitante de transferência de massa. A caracterização indicou elevados teores de DQO $\left(819 \mathrm{mg} \mathrm{L}^{-1}\right)$ e zinco $\left(504 \mathrm{mg} \mathrm{L}^{-1}\right)$. Nos experimentos de equilíbrio obteve-se capacidades de remoção de 129,20 e $280,55 \mathrm{mg} \mathrm{g}^{-1}$ para a solução sintética e o efluente real, respectivamente. A difusão intrapartícula controlou o processo global, sendo que foi possível predizer o comportamento cinético do efluente real a partir dos dados da solução sintética, apresentando um tempo de equilíbrio em torno de $420 \mathrm{~min}$. O processo de troca iônica utilizando a resina Amberlite IR 120 , portanto, mostra-se como um processo eficaz na remoção do cátion $\mathrm{Zn}^{2+}$ de efluentes líquidos de galvanoplastia.
\end{abstract}

\section{INTRODUÇÃO}

Devido ao rápido desenvolvimento e crescimento das indústrias, tem-se observado um aumento significativo nos níveis de contaminação dos corpos hídricos. Dentre as mais variadas formas de contaminação, os principais poluentes são os metais pesados (MÓDENES et al., 2013), que recebem especial atenção, por serem componentes não degradáveis, apresentando elevado caráter tóxico e contínua mobilização antropogênica no ambiente (FERREIRA et al., 2010; HUGEN et al., 2013). Em meio aos setores industriais, as indústrias de galvanoplastia têm ganhado bastante destaque nos últimos anos, por apresentarem um elevado potencial poluidor, devido as grandes quantidades de efluentes líquidos gerados.

Para tratar o efluente gerado por essas indústrias, contendo metais pesados, uma alternativa é a troca iônica. O processo de troca iônica consiste basicamente em colocar em contato uma fase líquida contaminada, com uma fase sólida (resina/trocador iônico), de modo que um ou mais componentes da fase líquida sejam transferidos para a fase sólida. $\mathrm{O}$ comportamento da troca iônica depende basicamente da natureza das espécies iônicas, como tamanho, carga e grau de hidratação do 
íon, temperatura do sistema, concentração das espécies em solução, do solvente empregado e da característica estrutural do trocador iônico (FU e WANG, 2011). Este processo tem como vantagens, frente aos outros métodos, a remoção seletiva dos íons, elevada eficiência, e a reversibilidade, onde após a saturação do trocador iônico, o mesmo pode ser regenerado com uma solução apropriada.

A utilização da modelagem matemática e a simulação computacional como ferramenta no desenvolvimento e avaliação de um processo, possibilitam a elaboração de projetos, o scale-up e a otimização equipamentos. Desta forma, o emprego de modelos adequados, que auxiliam na compreensão do fenômeno e na identificação dos mecanismos relevantes no processo são de fundamental importância (MARIN et al., 2014).

Portanto, o objetivo deste trabalho foi avaliar o potencial da remoção de zinco presentes em: (a) solução sintética; e (b) no efluente líquido proveniente de uma indústria de galvanoplastia pelo processo de troca iônica utilizando a resina catiônica Amberlite IR 120 e realizar a modelagem da cinética e equilíbrio do processo.

\section{MATERIAIS E MÉTODOS}

\subsection{Materiais}

A resina sintética Amberlite IR120 utilizada como trocador iônico foi fabricada pela Dow Chemical Company. Para realizar os experimentos de troca iônica, foram utilizados um efluente real fornecido por uma indústria de galvanoplastia de pequeno porte localizada na região oeste do Paraná, cidade de Cascavel, além de soluções sintéticas baseadas na concentração de metais pesados, conforme caracterização do efluente real.

\subsection{Métodos}

\subsubsection{Caracterização do efluente} Inicialmente, realizou-se a caracterização do efluente real, quanto a suas propriedades físico-químicas conforme a Tabela 1.

Tabela 1. Técnicas analíticas físico-químicas.

\begin{tabular}{ll}
\hline Técnicas & $\begin{array}{l}\text { Identificação } \\
\text { (Quantificação) }\end{array}$ \\
\hline $\begin{array}{l}\text { Espectrometria de } \\
\text { Fluorescência de Raio-X } \\
\text { (TXRF) }\end{array}$ & Metais Pesados \\
$\begin{array}{l}\text { Potencial Hidrogeniônico } \\
(\mathrm{pH})\end{array}$ & $\begin{array}{l}\text { Acidez, } \\
\text { Neutralidade ou }\end{array}$ \\
Atandard Methods $-22^{\text {th }}$ & Alcalinidade \\
$\begin{array}{l}\text { Edition: 2011 - 5220D } \\
\text { Standard Methods }-22^{\text {th }}\end{array}$ & (DQO) \\
$\begin{array}{l}\text { Edition: 2011 - 5520D } \\
\text { Standard Methods }-22^{\text {th }}\end{array}$ & Óleos e graxas \\
Edition: 2011 - 4500P & Fosfatos \\
Standard Methods $-22^{\text {th }}$ & Sulfatos \\
Edition: 2011 - A e E & \\
\hline
\end{tabular}

\subsubsection{Testes preliminares}

Foram realizados testes preliminares de troca iônica em sistema fechado e batelada para avaliar o efeito dos parâmetros $\mathrm{pH}$ inicial e quantidade de matéria orgânica. Os experimentos foram realizados em frascos Erlenmeyer de $125 \mathrm{~mL}$, utilizando como volume do efluente real $75 \mathrm{~mL}$, aos quais foram adicionados $0,1 \pm 0,0001 \mathrm{~g}$ de massa de resina sintética Amberlite IR 120 em cada experimento e colocados em mesa agitadora orbital (Tecnal TE-424) sob agitação e temperatura constante em $110 \mathrm{rpm}$ e $25 \pm 1^{\circ} \mathrm{C}$, respectivamente, durante um período de 24 horas. Foram avaliados o efeito dos seguintes parâmetros: $\mathrm{pH}$ inicial do efluente real $(2 ; 3 ; 4$; $5 ; 6 ; 6,5)$, os quais foram ajustados com solução de $\mathrm{HCl}\left(0,1 \mathrm{~mol} \mathrm{~L}^{-1}\right)$. No melhor condição operacional de $\mathrm{pH}(3,5)$ foi realizado a determinação de DQO em relação a concentração de metais pesados presentes no meio.

\subsubsection{Teste cinético}

Os experimentos de cinética foram realizados em frascos Erlenmeyer de $125 \mathrm{~mL}$, utilizando-se volume de efluente real/solução sintética de $75 \mathrm{~mL}$ no $\mathrm{pH} 3,5$, aos quais foram 
adicionados $0,1 \pm 0,0001 \mathrm{~g}$ de massa de resina sintética Amberlite IR 120. Os experimentos foram colocados em mesa agitadora orbital (Tecnal TE-424) sob agitação e temperatura constante em $110 \mathrm{rpm}$ e $25 \pm 1{ }^{\circ} \mathrm{C}$, respectivamente, durante um período de 10 horas, onde as amostras eram coletadas em tempos pré-determinados $(5,10,15,30,60$, $120,240,300,360,420,480,540$ e 600 minutos). Ao término de cada coleta, o efluente real/solução sintética era separado da resina e analisado em AAS quanto a concentração de metais. A concentração dos metais pesados na resina foi obtida por meio de um balanço de massa, representado pela Equação (1).

$$
q=\frac{\left(C_{0}-C\right) V}{m}
$$

Sendo, $q$ é concentração do metal na resina $\left(\mathrm{mg} \mathrm{g}^{-1}\right) ; C_{0}$ e $C$ são as concentrações iniciais e finais do corante nas soluções $\left(\mathrm{mg} \mathrm{L}^{-1}\right)$, respectivamente; $V$ é o volume da solução de efluente (L) e $m$ a massa seca da resina $(\mathrm{g})$.

\subsubsection{Teste de equilíbrio}

Os experimentos de isotermas de adsorção/troca iônica foram realizados em sistema fechado e batelada para efluente real e solução sintética ambos em pH 3,5. Em frascos Erlenmeyer de $125 \mathrm{~mL}$, contendo um volume de $75 \mathrm{~mL}$ de efluente real/solução sintética, aos quais foram adicionados diferentes quantidades de massa de resina sintética Amberlite IR 120 (0,02 a 1,0 g). Os ensaios foram mantidos em mesa agitadora orbital (Tecnal TE-424) sob agitação e temperatura constante em $110 \mathrm{rpm}$ e $25 \pm 1{ }^{\circ} \mathrm{C}$, respectivamente, durante um período de 10 horas, tempo necessário para que o equilíbrio fosse atingido. Ao final do experimento, $\mathrm{o}$ efluente real/solução sintética foi separado da resina e analisado em AAS quanto a concentração de zinco. A concentração de zinco na resina foi determinada pelo balanço de massa, conforme Equação (1).

\subsubsection{Modelagem matemática}

$\mathrm{Na}$ descrição do equilíbrio de adsorção empregou-se a isoterma de Langmuir (LANGMUIR, 1918), conforme a Equação (2).

$$
\bar{q}_{e}=\frac{q_{\max } b C_{e}}{1+b C_{e}}
$$

Sendo, $\bar{q}_{e}$ a concentração de metal na fase sólida no equilíbrio $\left(\mathrm{mg} \mathrm{g}^{-1}\right) ; C_{e}$ a concentração de metal na fase líquida no equilíbrio $\left(\mathrm{mg} \mathrm{L}^{-1}\right)$; $q_{\max }$ capacidade máxima de adsorção $\left(\mathrm{mg} \mathrm{g}^{-1}\right)$; e $b$ coeficiente de afinidade de Langmuir (L $\mathrm{mg}^{-1}$ ).

Para a identificação da etapa de transferência de massa limitante do processo os dados cinéticos foram avaliados segundo quatro diferentes modelos: (i) resistência à transferência de massa externa; (ii) resistência à transferência de massa interna; (iii) resistência à transferência de massa interna com $\mathrm{k}_{\mathrm{s}}$ variável; e (iv) adsorção nos sítios do adsorvente.

Na elaboração do modelo, apesar de se tratar um processo de troca iônica, o mesmo foi tratado como um processo de adsorção, ou seja, não foi avaliado a saída de espécies para a solução. $\mathrm{O}$ modelo de adsorção em sistema fechado e batelada foi baseada nas seguintes considerações: Processo isotérmico e isobárico; Propriedades físicas constantes nas fases sólida e líquida; Equilíbrio termodinâmico na interface líquido-sólido; e Mistura perfeita. Em todos modelos, o balanço de massa na fase líquida foi descrito pela Equação (1). A transferência de massa limitada pela difusão no filme foi descrita conforme a Equação (3).

$$
\frac{\partial \bar{q}(t)}{\partial t}=\frac{k_{F}}{\rho_{S}}\left[C(t)-C_{e}(t)\right]
$$

Sendo, $k_{F}$ o coeficiente volumétrico de transferência de massa no filme líquido 
externo $\left(\mathrm{min}^{-1}\right)$ e $\rho_{S}$ a massa específica do sólido $\left(\mathrm{g} \mathrm{L}^{-1}\right)$.

A possibilidade de resistência à transferência de massa interna e limitação pela difusão intrapartícula foi avaliada por uma aproximação da lei de Fick, denominado modelo da força motriz linear (linear driving force - $L D F)$, originalmente proposto por Glueckauf and Coates (MARIN et al., 2014), conforme Equação (4).

$$
\frac{\partial \bar{q}(t)}{\partial t}=k_{S}\left[\bar{q}_{e}(t)-\bar{q}(t)\right]
$$

Sendo, $\bar{q}_{e}$ a concentração média do metal na fase sólida $\left(\mathrm{mg} \mathrm{g}^{-1}\right)$ e $k_{S}$ o coeficiente de transferência de massa volumétrico no sólido $\left(\min ^{-1}\right)$.

Neste modelo, também foi avaliada uma modificação considerando-se um coeficiente de transferência de massa variável (modelo iii) em função da concentração do metal na fase sólida (CRANK, 1975), conforme a Equação (5).

$$
k_{S}=k_{S 0} \frac{1}{1+A \bar{q}(t)}
$$

Sendo, $k_{S O}$ o coeficiente de transferência de massa volumétrico no sólido para o estágio inicial do processo $\left(\mathrm{min}^{-1}\right)$; e $A$ um parâmetro ajustável $\left(\mathrm{g} \mathrm{mg}^{-1}\right)$.

Finalmente, a possibilidade da transferência de massa controlada pela adsorção nos sítios foi descrita pelo modelo de Thomas (1948), o qual se reduz à isoterma de Langmuir no equilíbrio, descrito pela Equação (6).

$$
\frac{\partial \bar{q}(t)}{\partial t}=k_{a}\left(q_{\max }-\bar{q}(t)\right) C(t)-\frac{k_{a}}{b} \bar{q}(t)
$$

Sendo, $k_{a}$ a constante cinética de adsorção (L $\left.\mathrm{mg}^{-1} \min ^{-1}\right), \quad k_{d}$ a constante cinética de dessorção $\left(\min ^{-1}\right)$, a qual relaciona-se com a constante de afinidade $b=k_{a} / k_{d}$.
As condições iniciais utilizadas na resolução dos modelos são dadas pelas Equações (7) e (8).

$$
\begin{aligned}
& C(0)=C_{0} \\
& q(0)=0
\end{aligned}
$$

Os sistemas de equações dos modelos, juntamente com as condições iniciais foram resolvidos pelo método Runge-Kutta-Fehlberg (RKF), utilizando-se o software Maple ${ }^{\circledR}$. A identificação dos parâmetros das isotermas de equilíbrio baseou-se na busca da minimização da função objetivo descrita pela Equação (9), pelo método de otimização downhill simplex desenvolvido por Nelder and Mead (1965). Ao passo que os parâmetros dos modelos cinéticos $\left(k_{F}, k_{S o}\right.$ e $\left.k_{a}\right)$ na minimização da FO dada pela Equação (10).

$$
\begin{aligned}
& F O=\sum_{j=1}^{N}\left(\bar{q}_{e, j}^{\text {exp }}-\bar{q}_{e, j}^{\text {mod }}\right)^{2} \\
& F O=\sum_{j=1}^{N}\left(\frac{C^{\text {exp }}-C^{\text {mod }}}{C^{\exp }}\right)^{2}
\end{aligned}
$$

Sendo, $N$ o número de dados experimentais de equilíbrio; $\bar{q}_{e, j}^{\exp }$ e $\bar{q}_{e, j}^{\text {mod }}$ são as concentrações média de metal na fase sólida no equilíbrio obtidos pelos dados experimentais e pelo modelo, respectivamente; $e C^{\text {mod }}$ as concentrações do metal na fase líquida em um dado tempo, obtidos pelas dados experimentais e pelos modelos cinéticos, respectivamente.

\section{RESULTADOS E DISCUSSÃO}

\subsection{Caracterização do efluente}

$\mathrm{Na}$ Tabela 2 são apresentados os resultados da caracterização do efluente real bruto da indústria de galvanoplastia e do efluente real submetido previamente a um processo de filtração (membrana de acetato de celulose, $\left.d_{\text {poros }}=0,45 \mu \mathrm{m}\right)$. O efluente filtrado apresentou uma diminuição na (DQO) e na 
concentração dos metais pesados, principalmente para o $\mathrm{Zn}$.

Os metais pesados removidos pelo processo de filtração, provavelmente, estavam aderidos a matéria-orgânica formando complexos com diâmetros equivalentes maiores que $0,45 \mu \mathrm{m}$. Contudo, além dos metais pesados na forma iônica, o efluente contém metais pesados formando colóides micelares com a matéria orgânica, uma vez que a quantidade de matéria orgânica e metais pesados reduziram com o processo de filtração. Como o efluente avaliado não cumpre as especificações segundo a legislação para lançamentos em corpos hídricos $\left(5 \mathrm{mg} \mathrm{L}^{-1} \mathrm{de}\right.$ $\mathrm{Zn}$ ), este efluente deve ser submetido a outros tipos de tratamento antes de seu descarte.

Tabela 2. Caracterização do efluente real bruto e do efluente real filtrado.

\begin{tabular}{ccc}
\hline $\begin{array}{c}\text { Parâmetros } \\
\text { Avaliados }\end{array}$ & $\begin{array}{c}\text { Efluente real } \\
\text { bruto }\left(\mathbf{m g ~ L}^{-1}\right)\end{array}$ & $\begin{array}{c}\text { Efluente real } \\
\text { filtrado } \\
\left(\mathbf{m g ~ L}^{-1}\right)\end{array}$ \\
\hline DQO & 819 & 738 \\
pH & 6,5 & 6,5 \\
Sulfatos & 49 & - \\
Óleos e & 0,4 & - \\
Graxas & 2,1 & - \\
Fosfatos & 1,7 & 1,4 \\
Níquel & 0,6 & 0,4 \\
Ferro & 1,5 & 1,4 \\
Bromo & 504 & 450 \\
Zinco & &
\end{tabular}

\subsection{Especiação do Zn em meio aquoso}

Considerando a concentração dos cátions metálicos $\left(\mathrm{Zn}^{2+}, \mathrm{Fe}^{2+}\right.$ e $\left.\mathrm{Ni}^{2+}\right)$, e do ânion sulfato $\left(\mathrm{SO}_{4}{ }^{2-}\right)$, de acordo com a caracterização do efluente, o diagrama de especiação foi simulado (Hydrochemical Equilibrium Constant Database - HYDRA, plug-in do aplicativo Make Equilibrium Diagrams Using Sophisticated Algorithms MEDUSA) para a seguinte mistura em meio aquoso: $\mathrm{Zn}-\mathrm{Ni}-\mathrm{Fe}-\mathrm{SO}_{4}$. Na Figura 1 é apresentado o diagrama de especiação para o metal $\mathrm{Zn}$ em função do $\mathrm{pH}$, considerando as outras espécies no meio aquoso. É importante ressaltar que o diagrama de especiação foi realizado considerando somente as propriedades das soluções aquosas (concentração, pH, força iônica).

Quando um sal MxXm é introduzido em uma solução aquosa, nem todas as moléculas dissociam-se em íons imediatamente. Desta forma, não são todas as espécies em solução que estão na forma de íons livres e podem participar do processo de troca iônica. A fração de íons livres em solução é dependente do $\mathrm{pH}$ do meio aquoso. Para o sistema $\mathrm{Zn}-\mathrm{Ni}-\mathrm{Fe}-\mathrm{SO} 4$ a faixa de $\mathrm{pH}$ predominante para íons livre $\mathrm{Zn}^{2+}$ é de $0-4,5$. Nesta faixa de $\mathrm{pH}$ segundo o diagrama de especiação, 93,5\% do zinco é encontrado na sua forma iônica $\left(\mathrm{Zn}^{2+}\right)$ enquanto $6,5 \%$ na forma do sal sulfato de zinco $\left(\mathrm{ZnSO}_{4}\right)$. A partir do $\mathrm{pH}$ de 4,5 , os íons metálicos $\mathrm{Zn}^{2+}$ diminuem drasticamente favorecendo assim a formação de complexos metálicos e cristais.

Figura 1. Diagrama de especiação do zinco no sistema $\mathrm{Zn}-\mathrm{Ni}-\mathrm{Fe}-\mathrm{SO}_{4}$ em função do $\mathrm{pH}$.

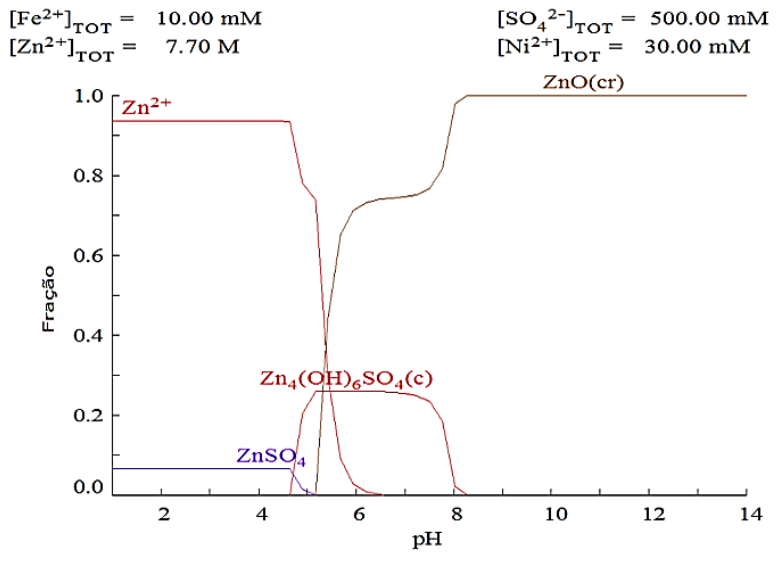

\subsection{Efeito do $\mathrm{pH}$ inicial na remoção de $\mathrm{Zn}$}

$\mathrm{Na}$ Figura 2, são apresentados o efeito da variação do $\mathrm{pH}$ inicial na remoção do metal $\mathrm{Zn}$ do efluente real bruto e do efluente real previamente filtrado. Nos valores de $\mathrm{pH} 2$ a 5 foi verificado uma maior remoção do metal $\mathrm{Zn}$ para o efluente real previamente filtrado. Isto pode estar relacionado a diminuição da matéria orgânica presente no meio, a qual pode obstruir os poros da resina dificultando o processo de transferência de massa da espécie $\mathrm{Zn}$ da fase 
líquida para a resina. Para os valores de $\mathrm{pH} 6 \mathrm{e}$ 6,5, o efluente real filtrado apresentou uma menor remoção do metal zinco. Nestas condições a presença do íon $\mathrm{Zn}^{2+}$ é extremamente baixa (3\%), sendo favorável a formação dos complexos (25\%) e cristais (71\%), os quais podem ser removidos no processo de filtração. Com isso, ocorre diminuição da concentração do metal $\mathrm{Zn}$ no efluente previamente filtrado, diminuido a força motriz para a transferência de massa do $\mathrm{Zn}$ entre as fases.

Figura 2. Concentração de $\mathrm{Zn}$ na resina em função do $\mathrm{pH}_{\text {inicial }}$ para: - Efluente real filtrado; • Efluente real não filtrado.

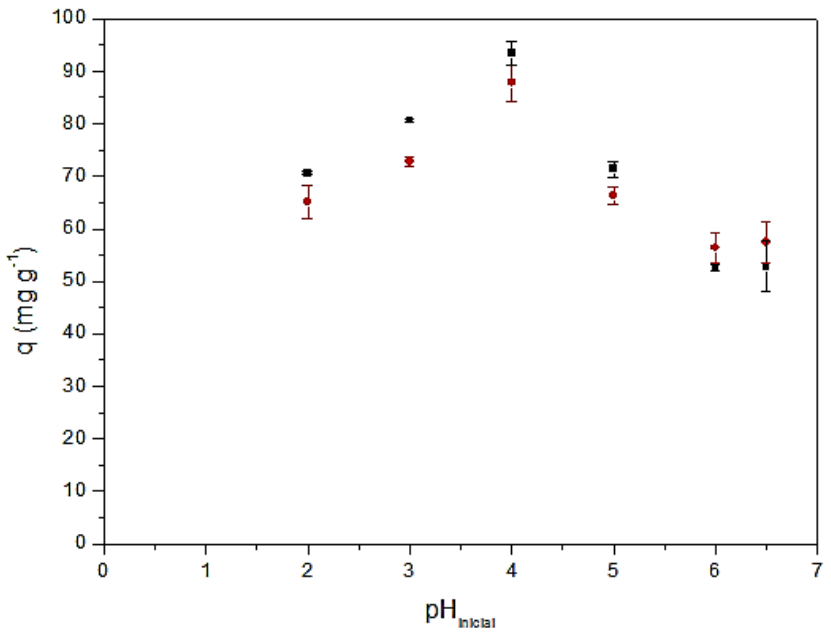

No experimento realizado em sistema fechado e batelada o $\mathrm{pH}$ foi medido ao final de cada experimento. $\mathrm{O} \mathrm{pH}$ representa a atividade do íon hidrogênio na água resultante inicialmente da dissociação da própria molécula da água e posteriormente acrescida pelo hidrogênio proveniente de outras fontes presentes nos efluentes industriais como: ácidos sulfúrico, clorídrico, nítrico, etc. Os resultados apresentados na Tabela 3 , mostram que houve um aumento do $\mathrm{pH}$ após o processo de troca iônica. Isto pode ser explicado pelo fato do efluente real possuir em sua composição matéria orgânica, ânions sulfatos $\left(\mathrm{SO}_{4}{ }^{2-}\right)$ e fosfatos $\left(\mathrm{PO}_{4}{ }^{3-}\right)$ que podem "sequestrar" o próton livre $\left(\mathrm{H}^{+}\right)$para a estabilização, diminuindo a quantidade de prótons livres em solução, consequentemente aumentando o $\mathrm{pH}$.

Tabela 3. Efeito do $\mathrm{pH}$ inicial no processo de troca iônica

\begin{tabular}{cccc}
\hline Experimentos & $\begin{array}{c}\text { Filtração } \\
(\text { membrana } \\
45 \mu \mathrm{m})\end{array}$ & $\mathrm{pH}_{\text {inicial }}$ & $\mathrm{pH}_{\text {final }}$ \\
\hline 1 & Não & 2,0 & 2,6 \\
2 & Sim & 2,0 & 2,6 \\
3 & Não & 3,0 & 3,5 \\
4 & Sim & 3,0 & 3,5 \\
5 & Não & 4,0 & 4,2 \\
6 & Sim & 4,0 & 4,2 \\
7 & Não & 5,0 & 5,2 \\
8 & Sim & 5,0 & 5,2 \\
9 & Não & 6,0 & 6,1 \\
10 & Sim & 6,0 & 6,1 \\
11 & Não & 6,5 & 6,5 \\
12 & Sim & 6,5 & 6,5 \\
\hline
\end{tabular}

Um outro importante aspecto que deve ser considerado e que pode afetar o $\mathrm{pH}$ no estudo de processos de troca iônica é a ocorrência de reações de hidratação. Uma grande razão carga/tamanho do cátion resulta em um aumento da energia de hidratação, onde os íons livres metálicos são complexados com a água se não ocorrer nenhuma reação além da coordenação das moléculas de água com o íon (Equação 11).

$\mathrm{M}^{+}+n \mathrm{H}_{2} \mathrm{O} \rightarrow\left[\mathrm{M}\left(\mathrm{H}_{2} \mathrm{O}\right)_{n}\right]^{+}$

As reações de hidrólise podem ocorrer quando a razão carga/tamanho do cátion é tão grande que provoque uma ruptura das ligações H-O com ionização do hidrato, liberando íons hidrônio. Neste caso ocorre há acidificação do meio. Em sistema fechado e batelada a concentração de metais pesados decresce até atingir a concentração de equilíbrio, este decréscimo pode estar relacionado com o aumento do $\mathrm{pH}$ ao final do experimento.

$\mathrm{O}$ pH afeta a especiação de íons metálicos em solução, ocorrendo um decréscimo de solubilidade dos complexos metálicos com o aumento de $\mathrm{pH}$. Valores de 
pH que promovem a precipitação dos complexos metálicos devem ser evitados durante experimentos de troca iônica, uma vez que a distinção entre a troca iônica e precipitação torna-se difícil (SCHIEWER e VOLESKY, 1995).

Contudo, o experimento que apresentou uma melhor remoção para a espécie $\mathrm{Zn}$ foi em $\mathrm{pH}_{\text {inicial }} 4,0$. Neste caso o $\mathrm{pH}_{\text {final }}$ foi de 4,2. Baseado no diagrama de especiação (ver Figura 1), onde a faixa predominante para íons livre $\mathrm{Zn}^{2+}$ é de 0 - 4,5 e a partir do aumento deste $\mathrm{pH}(4,5)$ ocorre a diminuição dos íons metálicos $\mathrm{Zn}^{2+}$ favorecendo a formação de complexos e cristais. Visto que durante o processo de troca iônica o $\mathrm{pH}_{\text {final }}$ sofreu alteração quanto a concentração e como o $\mathrm{pH}_{\text {final }}$ deste experimento esteve no limite para o favorecimento a formação de complexos, decidiu-se por trabalhar com $\mathrm{pH}$ igual a 3,5 para a realização dos demais experimentos em sistema fechado e batelada e em coluna de leito fixo. $\mathrm{O} \mathrm{pH}_{\text {inicial }} 3,5$ foi escolhido, pois uma possível variação do meio durante o processo não favoreceria a formação de complexos e cristais, e por ser um intermédio entre os valores de $\mathrm{pH} 3$ e 4 que foram os que apresentaram melhor remoção para a espécie $\mathrm{Zn}$.

\subsection{Equilíbrio de adsorção}

Na Figura 3 são apresentados os dados experimentais de equilíbrio obtidos utilizando a solução sintética de zinco e o efluente real filtrado. Os dados de equilíbrio obtidos para a solução sintética apresentam formato semelhante a isoterma de monocamada do tipo I, segundo a classificação da IUPAC (SING, 1982). Este tipo de isoterma está relacionada a adsorção de monocamada. $\mathrm{Na}$ literatura (ELABD et al., 2014; VEIT et al., 2013; DEMIRBAS et al., 2005) são reportados dados de equilíbrio para sistemas metais pesadosresina Amberlite IR 120. Nestes trabalhos foram obtidas isotermas favoráveis, apresentando características de isotermas do tipo I. Deve-se ressaltar que estes dados foram obtidos a partir de soluções sintéticas de metais.

Figura 3. Isotermas de equilíbrio de adsorção do zinco para (a) Solução sintética e (b) Efluente real. (Condições experimentais: $\mathrm{T}=25^{\circ} \mathrm{C} ; \mathrm{pH}_{\text {inicial }}=3,5$; $100 \mathrm{rpm})$.
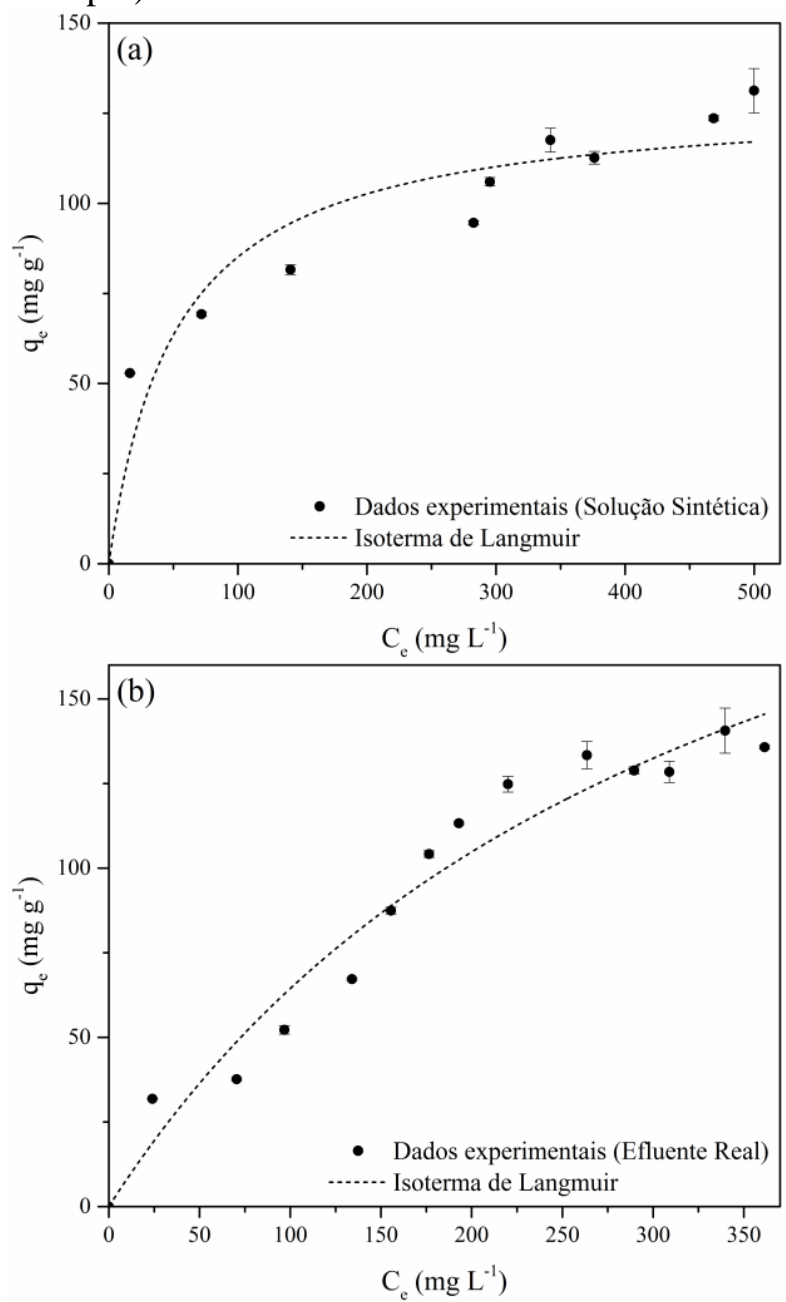

Para o efluente real, observa-se uma semelhança com a isoterma do tipo IV. O formato sigmoidal da isoterma obtida para o efluente real indica a possibilidade de formação de multicamadas (SING, 1982). No entanto, este não seria um comportamento esperado em sistemas de troca iônica. Logo, o formato desta isoterma pode estar a associado a formação de colóides micelares entre a matéria orgânica e o $\mathrm{Zn}$ sendo que estes 
colóides podem ocupar os sítios de troca iônica aumentando a remoção da espécie $\mathrm{Zn}$ do meio, conforme ilustrado na Figura 4b. Na Figura 4a é ilustrado o fenômeno esperado pelo processo de troca iônica, onde o íon $\mathrm{Zn}^{2+}$ ocupa o sítio ativo da resina.

Figura 4. Representação dos sítios ativos da resina Amberlite sendo ocupados pela espécie $\mathrm{Zn}$. (a) Solução sintética; (b) Colóides.

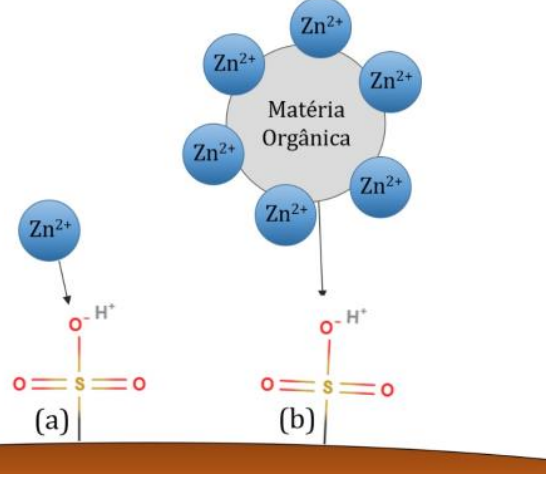

Na Tabela 4 são apresentados os parâmetros estimados da isoterma de Langmuir aos dados experimentais para a solução sintética e o efluente real.

Tabela 4. Parâmetros estimados da isoterma de Langmuir aos dados de equilíbrio para a adsorção do zinco.

\begin{tabular}{ccc}
\hline \multicolumn{3}{c}{ Isoterma de Langmuir } \\
\hline Parâmetro & Solução sintética & Efluente real \\
\hline $\boldsymbol{q}_{\max }\left(\mathbf{m g ~ g}^{-1}\right)$ & $129,20 \pm 96,93$ & $280,55 \pm 48,86$ \\
$\boldsymbol{b}\left(\mathbf{L} \mathbf{~ m g}^{-1}\right)$ & $0,0193 \pm 0,0076$ & $0,0030 \pm 0,0009$ \\
$\boldsymbol{r}^{2}$ & 0,91 & 0,95 \\
$\chi^{2}$ & 148,47 & 97,36 \\
\hline
\end{tabular}

Observando-se o valor do coeficiente de correlação, juntamente com a interpretação gráfica dos modelos, verifica-se que a isoterma se ajustou aos dados experimentais de adsorção do zinco na resina Amberlite. Observa-se que o efluente real apresentou capacidade de adsorção superior a solução sintética, o que pode ser atribuído à adsorção dos colóides miscelares. No entanto, o coeficiente de afinidade é superior para a solução sintética, indicando uma maior afinidade entre o íon $\mathrm{Zn}^{2+}$ em solução com a resina do que o efluente real.

\subsection{Cinética de adsorção}

$\mathrm{Na}$ Figura 5 são apresentados os dados experimentais da cinética de remoção do zinco, juntamente com a modelagem dos dados obtidos utilizando: (a) solução sintética de $\mathrm{Zn}^{2+}$ e (b) efluente real previamente filtrado.

Figura 5. Cinética de adsorção do zinco para (a) Solução sintética; e (b) Efluente real (Condições experimentais: $\mathrm{T}=25^{\circ} \mathrm{C} ; \mathrm{pH}_{\text {inicial }}=3,5 ; 100 \mathrm{rpm}$ ).
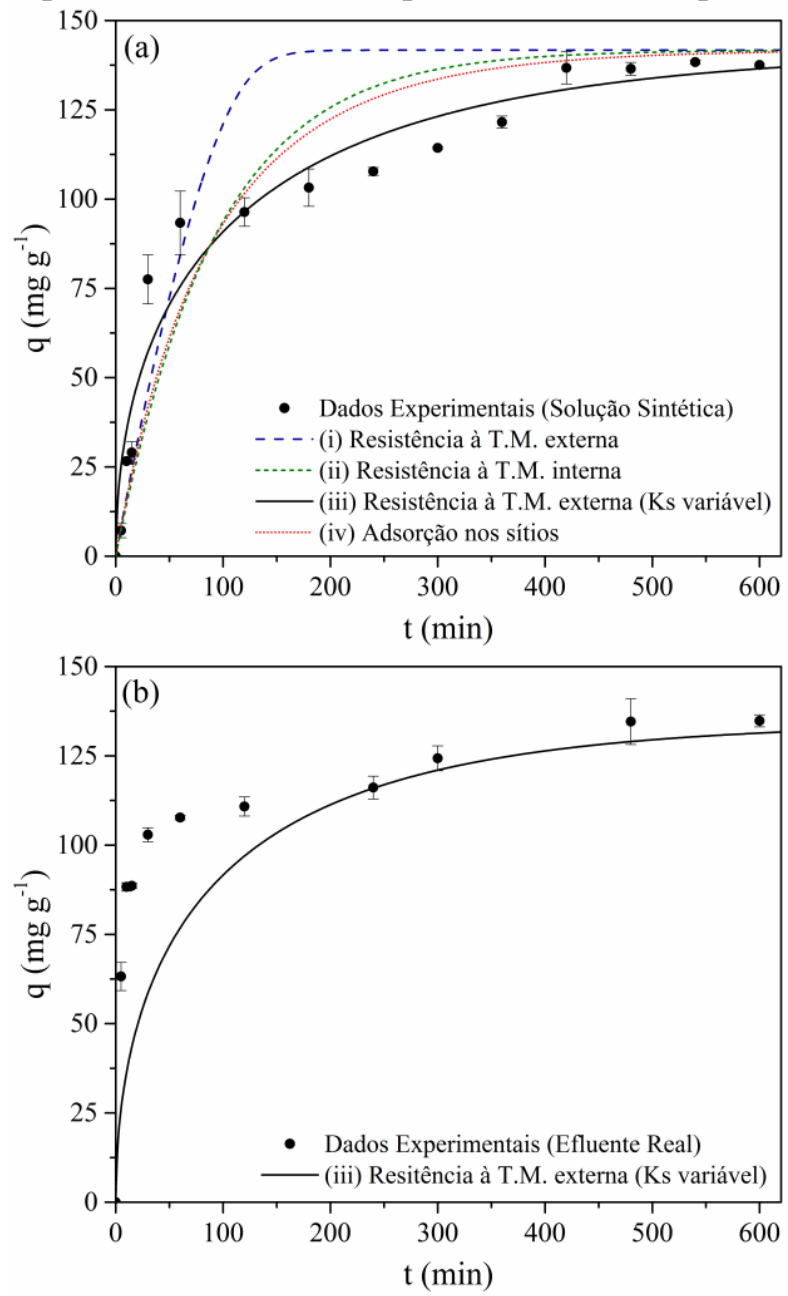

Analisando o comportamento da cinética para o efluente real e a solução sintética, observou-se que ambas apresentaram uma capacidade de remoção da espécie $\mathrm{Zn}$ similar, com um tempo de equilíbrio de aproximadamente $420 \mathrm{~min}$. 
Os modelos difusivos e de adsorção foram empregados com intuito de identificar a etapa limitante de transferência de massa. É possível verificar que o modelo que melhor se ajustou aos dados experimentais para a solução sintética (Fig. 5a) foi o modelo de resitência à T.M. com $k_{S}$ variável (modelo iii). Indicando que a difusão do zinco na partícula sólida da resina é significativa na cinética do processo e controla o processo global, e ainda que a cinética de adsorção diminui à medida que a concentração do metal aumenta na resina.

$\mathrm{Na}$ Tabela 5 são apresentados os valores dos parâmetros estimados para cada um dos modelos cinéticos avaliados para a solução sintética de zinco.

Tabela 5. Parâmetros estimados dos modelos cinéticos para a solução sintética e a predição para o efluente real.

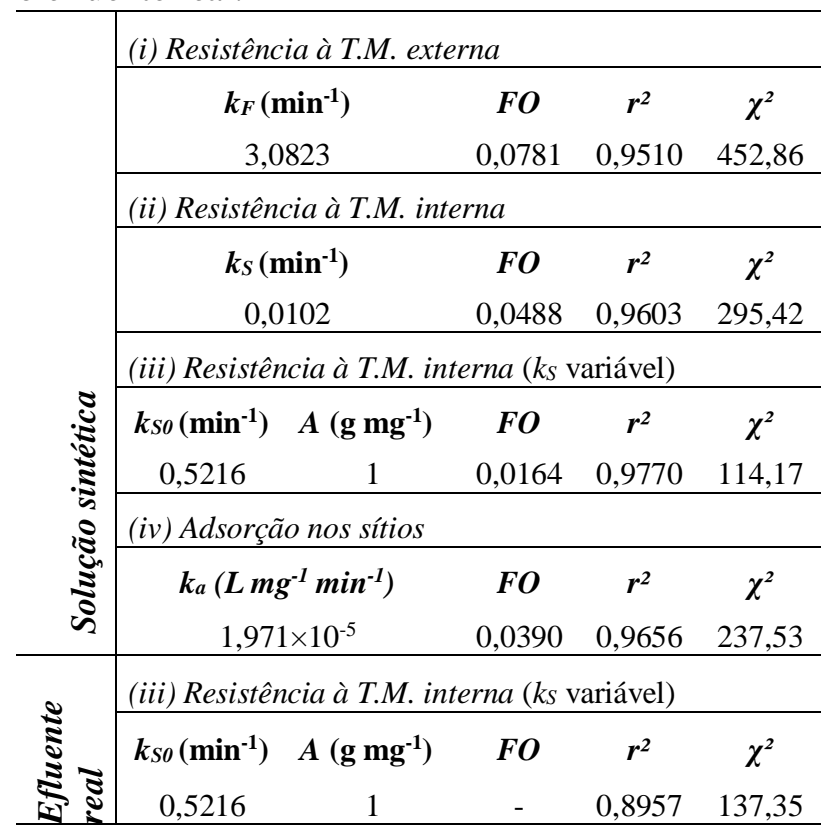

Observando-se os valores a $F O, r^{2} e \chi^{2}$ verifica-se que o modelo de resistência à transferência de massa interna com $k_{S}$ variável descreveu os resultados cinéticos para a solução sintética de zinco. Desta forma, utilizou-se este modelo para realizar a predição dos dados cinéticos do efluente real. Utilizando os mesmos parâmetros do modelo $\left(k_{s o}=\right.$
$0,5216 \mathrm{~min}^{-1}$ e $\mathrm{A}=1 \mathrm{~g} \mathrm{mg}^{-1}$ ) obteve-se um coeficiente de correlação de 0,8957 , ou seja, $89 \%$ dos valores experimentais do efluente real são explicados pelo modelo.

Analisando a Figura 5b é possível notar que o modelo não prevê os dados no início do processo $(\mathrm{t}<100 \mathrm{~min}$ ), no entanto é capaz de prever o seu equilíbrio. Este comportamento, pode estar relacionado com o fato de que no efluente real uma grande quantidade de substâncias como, por exemplo, óleos e graxas e matéria-orgânica afetam a cinética de adsorção do metal, como observado na caracterização do mesmo (Tabela 2).

Deste modo, tanto a isoterma quanto a cinética do processo são influenciadas pelos constituintes presentes no meio aquoso. Podendo afetar os parâmetros físico-químicos do sistema como, por exemplo, a força iônica do meio, a viscosidade do solvente, o nível de agregação das moléculas e dos íons zinco (formação de colóides micelares), dentre outros. Influenciando, consequentemente, tanto a difusão das espécies quanto as interações entre o adsorbato e a superfície da resina. No entanto, apesar destes interferentes o modelo de resistência à transferência de massa interna com $k_{S}$ variável foi capaz de descrever os dados cinéticos para a solução sintética e a partir destes dados predizer os dados cinéticos de remoção do zinco presente no efluente real de galvanoplastia.

\section{CONCLUSÃO}

A caracterização do efluente real de galvanoplastia indicou valores expressivos de DQO e zinco, 819 e $504 \quad \mathrm{mg}^{-1}$, respectivamente. Além da presença de sulfatos, fosfatos, óleos e graxas e outros metais pesados em quantidades inferiores. Desta forma, avaliou-se a influência do $\mathrm{pH}$ inicial na remoção de zinco. Baseado nos testes de remoção, juntamente com a simulação da especiação do zinco considerou-se o $\mathrm{pH} 3,5$ como a melhor condição a fim de evitar a 
precipitação do mesmo. No estudo de cinética e equilíbrio verificou-se capacidades de remoção similares entre a solução sintética e o efluente real. No entanto, verificou-se a possibilidade de formação de coloides micelares, os quais afetam o comportamento da remoção do metal. Finalmente, os modelos matemáticos empregados foram capazes de auxiliar na identificação da etapa limitante na transferência de massa, neste caso a difusão interna do íon $\mathrm{Zn}^{2+}$ na resina Amberlite. Além disso, o modelo proposto foi capaz de predizer os dados do efluente real a partir dos parâmetros estimados para a solução sintética. Desta forma, este tipo de avaliação pode ser utilizada como uma ferramenta eficiente para o scale-up e otimização do processo de remoção do zinco de efluentes de galvanoplastia, tanto em batelada quanto em colunas de leito fixo.

\section{REFERÊNCIAS}

CRANK J. The mathematics of diffusion. 2nd ed. Oxford: Clarendon Press, 1975.

DEMIRBAS, A.; PEHLIVAN, E.; GODE, F.; ALTUN, T.; ARSLAN, G. Adsorption of $\mathrm{Cu}$ (II), Zn (II), Ni (II), Pb (II) and Cd (II) from aqueous solution on Amberlite IR120 synthetic resin. Journal of Colloid and Interface Science, v.282, p.20-25, 2005.

ELABD, A.A.; ZIDAN, W.I.; ABO-ALY, M.M.; BAKIER, E.; ATTIA, M.S. Uranyl ions adsorption by novel metal hydroxides loaded Amberlite IR120. Journal of Environmental Radioactivity 134, p.99-108, 2014.

FERREIRA, A.P.; HORTA, M.A.P.; CUNHA, C.L.N. Avaliação das concentrações de metais pesados no sedimento, na água e nos órgãos de Nycticorax nycticorax (Garça-da-noite) na Baía de Sepetiba, RJ, Brasil. Revista da Gestão Costeira Integrada, v.10, p.229-241, 2010.

FU, F.; WANG, Q. Removal of heavy Metal Ions from wastewaters: A Review. Journal of
Environmental Management 92, p.407-418, 2011.

HUGEN, C.; MIQUELLUTI, D.J.; CAMPOS, M.L.; ALMEIDA, J.A.; FERREIRA, E.R.N.C.; POZZAN, M. Teores de $\mathrm{Cu}$ e $\mathrm{Zn}$ em perfis de solos de diferentes litologias em Santa Catarina. R. Bras. Eng. Agríc. Ambiental, v.17, n.6, p.622-628, 2013.

LANGMUIR, I. The adsorption of gases on plane surfaces of glass, mica and platinum. Journal of the American Chemical Society, v.40, n.9, p.1361-1403, 1918.

MARIN, P., BORBA, C.E., MÓDENES, A.N., ESPINOZA-QUIÑONES, F.R., OLIVEIRA, S.P.D., KROUMOV, A.D., Determination of the mass transfer limiting step of dye adsorption onto commercial adsorbent by using mathematical models. Environmental Technology, v.35, n.18, 2014.

MÓDENES, A.N.; ESPINOZA-QUIÑONES F.R.; LAVARDA, F.L.; COLOMBO A.; BORBA C.E.; LEICHTWEIS W.A.; MORA N.D. Remoção dos metais pesados Cd (II), Cu (II) e $\mathrm{Zn}$ (II) pelo processo de biossorção utilizando a macrófita Eicchornia crassipes. Esc. Minas, Ouro Preto, v.66, n.3, p.355-362, jul. set. 2013.

SCHIEWER, S.; VOLESKY, B. Modeling of the proton-metal ion exchange in biosorption. Environ. Sci. Tec., v.29, p.3049-3058, 1995.

SING, K.S.W. Reporting physisorption data for gas/solid systems with special reference to the determination of surface area and porosity. Pure Applied Chemistry, v.54, p.2201-2218, 1982.

VEIT, M.T.; FRANCO, P.E.; BORBA, C.E.; GONÇALVES, G.C.; FAGUNDES-KLEN, M.R.; BERGAMASCO, R.; SILVA, E.A.; SUZAKI, P.Y.R. Nickel (II) and zinc (II) removal using Amberlite IR-120 resin: Ion exchange equilibrium and kinetics. Chemical Engineering Journal 221, p.426-435, 2013. 